\title{
Max und Moritz: uma tradução comentada
}

\author{
Sigfrid Frömming
}

Resumo: Wilhelm Busch é autor de "Max und Moritz", obra publicada em 1865, que conta a história de dois meninos que aprontam traquinagens contra pessoas de uma vila sem nome. Um trabalho dessa envergadura e influência merece atenção e tradução constante. Neste trabalho, pretendeu-se aplicar as teorias descritivas de Peeter Torop a um extrato de texto, com os devidos comentários das escolhas tradutórias. De início tem-se a apresentação do autor do texto. Em seguida, uma pequena abordagem das teorias de Torop. No terceiro momento, 0 texto original e a sua tradução. Por fim, os comentários das escolhas tradutórias que demandaram mais cuidados. O trabalho em si mostra que é possivel aplicar a teoria referida a um texto infantil em versos, tal como apregoado por Torop.

Palavras-chave: Torop; Busch; tradução comentada; Max und Moritz;

\section{$O$ autor, Wilhelm Busch}

Heinrich Christian Wilhelm Busch nasceu em uma vila chamada Wiedensahl, em Stadthagen, perto de Hannover, Niedersachsen (Baixa Saxônia), em 15 de abril de 1832 e morreu em Mechtshausen em 09 de janeiro de 1908. Ele era o primogênito de sete filhos.

Busch queria ser pintor e desenhista. Sua fonte de inspiração eram os desenhos dos pintores holandeses do século XVII.

Em 1854, estudou na Academia de Arte de Munique. Em 1858, publicou a historinha Die Kleinen Honigdiebe no jornal Münchener Bilderbogen. $O$ traço marcante dessas histórias foi o fato de contá-las em desenhos e palavras (texto). Busch produziu cerca de 150 histórias contadas assim. 
Em 1864, numa fase pessoal conturbada e crítica, Busch escreveu a obra que o consagrou, cujos direitos autorais ele vendeu ao editor Kaspar Braun. Este a editou em 04 de abril de 1865, a saber: Max und Moritz: eine Bubengeschichte in Sieben Streichen. Tamanha importância fez Vaßen (1986, p. 96) classificá-la como "kleine Kinder-Epopöe", isto é, "pequena epopeia infantil".

As obras de Busch versam sobre a miséria deixada pela opressão em que vivia o proletariado e o camponês, tendo muitos tributos a pagar e as colheitas sendo dizimadas pelas pragas. Refletiam ainda a filosofia pessimista do autor em relação à vida e a aversão pela avareza e pelo materialismo, apontando o seu pensamento para os fracos e as falhas dos humanos. Também, lançou um olhar para o absurdo e a maldade praticada por quem regia o país àquela época: a pequena-burguesia (GLASER et. al., 1987, p. 370).

Quanto aos seus desenhos, ganham tanta dinâmica (movimento, sequência, simultaneidade) que antecipam as técnicas de filmagem de desenhos animados. Por esta razão ele é considerado o precursor das histórias em quadrinhos.

\section{Torop e suas teorias}

Peeter Torop é um estudioso da tradutologia da Escola de Tartu, na Estônia, que lançou um livro em 1995 com o título Total'nyj perevod, ou seja, "Tradução total". Nele aparecem não as teorias prescritivas da tradução, mas os aspectos descritivos. Analisando traduções feitas ao redor do mundo, Torop afirma que toda tradução pode ser total, dentro de seus propósitos, e pode ser de duas maneiras: recodificação (o texto é recodificado para o novo idioma) e transposição (o conteúdo é transposto para a nova cultura/língua). Ambas podem ser subdivididas mais uma vez, pois podem priorizar o ponto de vista da obra original (análise) ou o ponto de vista da tradução (síntese). Por sua vez, cada uma delas pode ser subdividida novamente, em centrada em dominante (destaca um aspecto escolhido pelo tradutor, mas admite aspectos secundários) ou autônoma (admite apenas um único aspecto na tradução). Isto resulta em 8 categorias de tradução, a saber, a recodificação analítica dominante macroestilística (predomina o macroestilo do texto original), a recodificação analítica autônoma precisa (palavra por palavra), a recodificação sintética dominante microestilística (predomina o estilo do autor), a recodificação sin- 
tética autônoma de citação (chamada de "literal"), a transposição analítica dominante temática (prioriza o tema), a transposição analítica autônoma descritiva (prioriza a descrição), a transposição sintética dominante expressiva (observa a expressão do texto) e a transposição sintética autônoma livre (em que há liberdade ampliada nas escolhas tradutórias) (OSIMO , 2004). Todas elas ainda são ajudadas pelo que Torop chama de parâmetros de traduzibilidade, que não serão aqui explicitados.

A tradução de recodificação analítica dominante macroestilística tem como dominante o plano da expressão do prototexto (original), que fornecerá a base para o plano de conteúdo do metatexto (tradução). Sua estrutura formal é perceptível e o estilo do original aparece num âmbito global. É mais comum e aplicável em poemas rimados e que conservam a métrica (OSIMO, 2004, cap. 22). Em outras palavras, o que interessa é a forma muito mais do que o conteúdo, se bem que o conteúdo será abordado por conta do estilo macro do texto, ou seja, o seu conjunto determinará o conteúdo, estando completamente apoiado na forma. É fácil perceber isso quando se traduz um poema que contenha rima, ritmo e métrica, como é o caso de Max und Moritz, formas que se procura transportar para o texto traduzido (metatexto). Podemos dizer que a opção pelo ritmo, pelas rimas e pela métrica, bem como o estilo humorístico, os desenhos e certa crítica aos valores sociais vigentes são marcadores do estilo Busch.

Neste aspecto, é salutar deixar todos os elementos possíveis do macroestilo. Permanecem as rimas, a métrica, os desenhos originais, o tom irônico em alguns momentos e a graça de algumas situações.

$O$ extrato de texto de Max und Moritz a seguir foi traduzido de acordo com a definição da tradução de recodificação analítica dominante macroestilística. Corresponde ao prólogo e à primeira travessura. Ao lado do original, aparece a proposta de tradução, que não é única nem definitiva. As figuras ${ }^{1}$ fazem parte do texto original.

\section{Original e tradução}

\begin{tabular}{|c|c|}
\hline $\begin{array}{c}\text { Max und Moritz. } \\
\text { Eine Bubengeschichte in } \\
\text { sieben Streiche }\end{array}$ & $\begin{array}{c}\text { Max e Moritz: } \\
\text { uma história, dois moleques, } \\
\text { sete troças }\end{array}$ \\
\hline
\end{tabular}

\footnotetext{
1 Todas as figuras são de autoria de Wilhelm Busch.
} 


\begin{tabular}{|l|l|}
\hline \multicolumn{1}{|c|}{ Vorwort } & \multicolumn{1}{c|}{ Prólogo } \\
Ach, was muß man oft von bösen & $\begin{array}{l}\text { Quanta história é contada } \\
\text { Kindern hören oder lesen! }\end{array}$ \\
Wie zum Beispiel hier von diesen, & $\begin{array}{l}\text { Demo exemplo, esses dois, } \\
\text { Comalada. }\end{array}$ \\
\hline
\end{tabular}

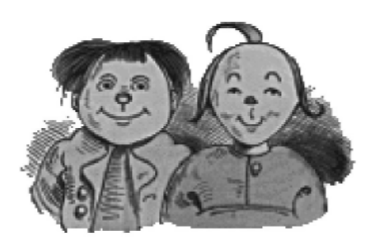

Welche Max und Moritz hießen, Die, anstatt durch weise Lehren Sich zum Guten zu bekehren, Oftmals noch darüber lachten Und sich heimlich lustig machten. $\mathrm{Ja}$, zur Übeltätigkeit, $\mathrm{Ja}$, dazu ist man bereit! Menschen necken, Tiere quälen! Äpfel, Birnen, Zwetschen stehlen Das ist freilich angenehmer Und dazu auch viel bequemer, Als in Kirche oder Schule Festzusitzen auf dem Stuhle. Aber wehe, wehe, wehe! Wenn ich auf das Ende sehe!! Ach, das war ein schlimmes Ding, Wie es Max und Moritz ging. Drum ist hier, was sie getrieben, Abgemalt und aufgeschrieben.
Max e Moritz, ora, pois: Ao invés de serem bons, Desvirtuam os seus dons. Acham graça da desgraça: Gostam de fazer trapaça. Pra maldade dizem "sim!"; Todo dia é sempre assim: Sempre os bichos maltratar: Das pessoas, só zombar. Roubar frutas, nem se fala! É melhor que ir pra escola! É melhor que ir pra igreja! Sentar lá não se deseja.

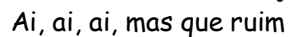
Quando observo o seu fim! Ah, que coisa, que desgraça Que o destino aqui traça! Eis escrito e desenhado Tudo o que têm aprontado.

\begin{tabular}{|l|l|}
\hline \multicolumn{1}{|c|}{ Erster Streich } & \multicolumn{1}{c|}{ Primeira travessura } \\
Mancher gibt sich viele Müh' & Ter galinhas no quintal \\
Mit dem lieben Federvieh; & É um hábito normal. \\
Einesteils der Eier wegen, & A primeira boa razão: \\
Welche diese Vögel legen, & Botam ovos de montão; \\
Zweitens: weil man dann und wann & A segunda causa é: \\
Einen Braten essen kann; & Substituem um bom filé; \\
Drittens aber nimmt man auch & A terceira circunstância: \\
Ihre Federn zum Gebrauch & Penas têm em abundância \\
In die Kissen und die Pfühle, & Pra coberta e travesseiro, \\
Denn man liegt nicht gerne kühle. & Pra espantar o frio ligeiro. \\
\hline
\end{tabular}




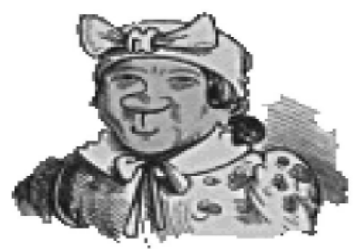

Seht, da ist die Witwe Bolte, Die das auch nicht gerne wollte.

Ihrer Hühner waren drei Und ein stolzer Hahn dabei. Max und Moritz dachten nun: Was ist hier jetzt wohl zu tun? -Ganz geschwinde, eins, zwei, drei, Schneiden sie sich Brot entzwei,
Quem não gosta que o frio volte É a tal viúva Bolte.

Um bom galo ela tem;

Três galinhas tem também. Max e Moritz não têm jeito: "O que pode aqui ser feito?" Rapidinho, 1, 2, 3,

Picadinho um pão se fez.

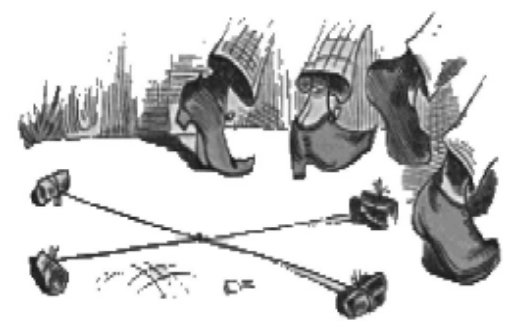

In vier Teile, jedes Stück Wie ein kleiner Finger dick. Diese binden sie an Fäden, Übers Kreuz, ein Stück an jeden, Und verlegen sie genau In den Hof der guten Frau. Kaum hat dies der Hahn gesehen, Fängt er auch schon an zu krähen:

Faz-se um xis com um barbante $E$ nas pontas, bem distante, Deixam um pedaço preso Num tamanho bem coeso. No quintal da boa senhora, Eles botam sem demora. Quando o galo viu aquilo, Abre o bico em grande estilo:

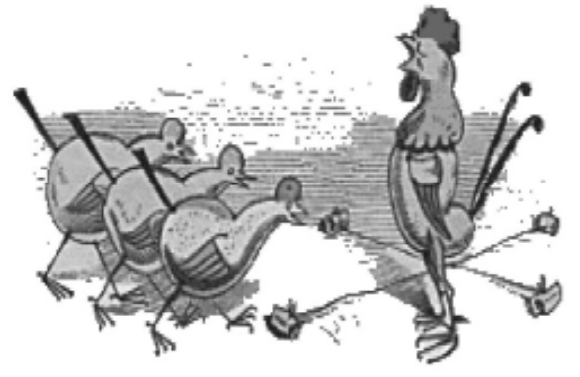




\begin{tabular}{|l|l|}
\hline $\begin{array}{l}\text { Kikeriki! Kikikerikih!! } \\
\text { Tak, tak, tak! - da kommen sie. }\end{array}$ & $\begin{array}{l}\text { Cocricó Cocoricó!!! } \\
\text { Lá vêm elas - Poc, poc, póó! }\end{array}$ \\
\hline
\end{tabular}

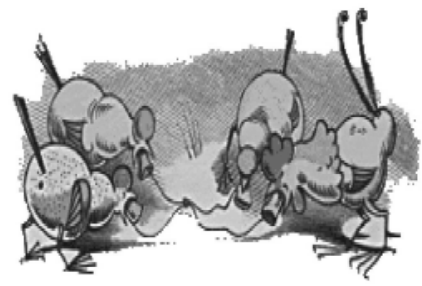

Hahn und Hühner schlucken munter

Cada um pega um pedaço Jedes ein Stück Brot hinunter: E engole com o laço.

\begin{tabular}{|l|l}
\hline $\begin{array}{l}\text { Aber als sie sich besinnen, } \\
\text { Konnte keines recht von hinnen. }\end{array}$ & $\begin{array}{l}\text { Terminando de papar, } \\
\text { Já não saem mais do lugar. }\end{array}$
\end{tabular}

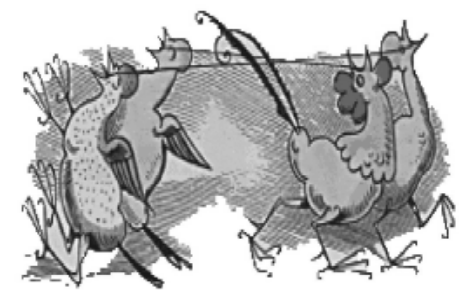

In die Kreuz und in die Quer Vão puxando o fio em cruz, Reißen sie sich hin und her, E seu fim já se deduz.

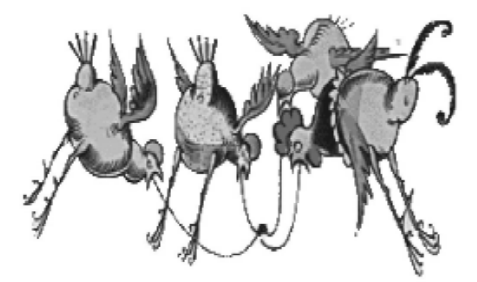

Flattern auf und in die Höh', Batem asas, saem do chão. Ach herrje, herrjemine! Ai, meu Deus, Jesus, João!

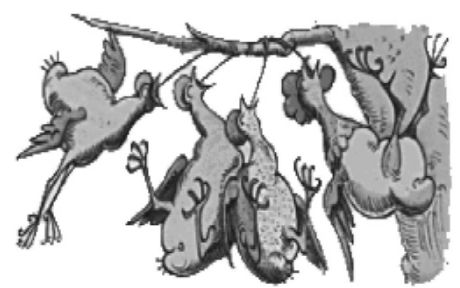


Ach, sie bleiben an dem langen, Dürren Ast des Baumes hangen. -Und ihr Hals wird lang und länger, Ihr Gesang wird bang und bänger:
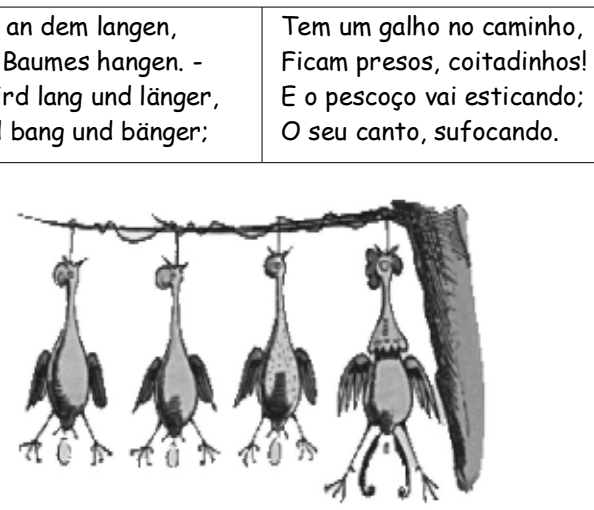

Jedes legt noch schnell ein $\mathrm{Ei}$, Und dann kommt der Tod herbei. -

Vendo que acabou a sorte, Põem um ovo, e vem a morte.

Witwe Bolte in der Kammer Hört im Bette diesen Jammer: Lá no quarto a boa senhora Um cochilo tira agora.

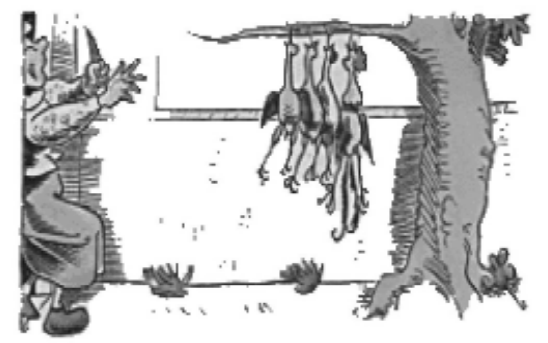

Ahnungsvoll tritt sie heraus: Ach, was war das für ein Graus!

Quando ouve o triste coro, Sai correndo e cai no choro:

"Fließet aus dem Aug', ihr Tränen! All mein Hoffen, all mein Sehnen, Meines Lebens schönster Traum "Que horror! Eu vou chorar! Hängt an diesem Apfelbaum! !" Onde o sonho foi parar?!! $O$ melhor que a vida deu Neste galho se perdeu!"

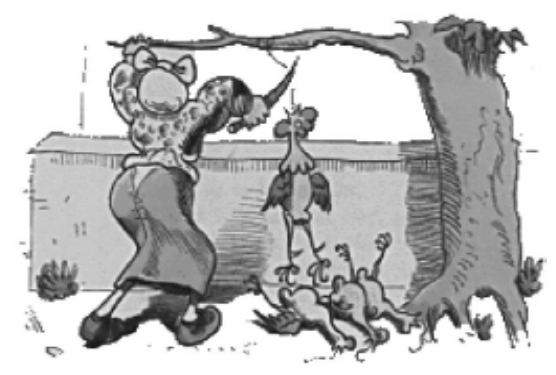




\begin{tabular}{|c|c|}
\hline $\begin{array}{l}\text { Tiefbetrübt und sorgenschwer } \\
\text { Kriegt sie jetzt das Messer her; } \\
\text { Nimmt die Toten von den Strängen, } \\
\text { Daß sie so nicht länger hängen. }\end{array}$ & $\begin{array}{l}\text { Abatida pra valer, } \\
\text { O seu bem não quer perder. } \\
\text { Com a faca em sua mão, } \\
\text { Tira os mortos do cordão. }\end{array}$ \\
\hline $\begin{array}{l}\text { Und mit stummem Trauerblick } \\
\text { Kehrt sie in ihr Haus zurück. - }\end{array}$ & $\begin{array}{l}\text { E com jeito triste e mudo, } \\
\text { Para dentro leva tudo. }\end{array}$ \\
\hline $\begin{array}{l}\text { Dieses war der erste Streich, } \\
\text { Doch der zweite folgt sogleich. }\end{array}$ & $\begin{array}{l}\text { A primeira aprontaram, } \\
\text { Mas os dois não sossegaram. }\end{array}$ \\
\hline
\end{tabular}

\section{Comentários a respeito das escolhas tradutórias}

Para contemplar a escolha da categoria tradutória de Torop, o público-alvo imaginado da tradução é formado por crianças em torno de 4 a 10 anos. Um fator que contribui nesta escolha está na própria história. Qual seria a idade de Max e Moritz? Teriam talvez entre oito e doze anos. Para Benton, o escritor não cria apenas o personagem, mas também o leitor. E a resposta (estímulo) que uma criança dá ao que lê está diretamente ligada à visão que encontra de si no livro que lê. Criança gosta de histórias curtas, sobre crianças com quem possa se identificar de alguma maneira (BENTON, 2002, p. 84).

Uma das primeiras decisões a tomar foi com relação à manutenção da forma do texto na tradução. Considerando os argumentos de Philip, existe uma tradição que pode ser notada e uma noção de que, através da poesia, um mundo é visto pela primeira vez por meio de uma linguagem como que caindo do céu, o que não quer dizer que os poemas infantis devam ser simplórios, pois todos os verdadeiros poemas carregam consigo um mistério (PHILIP, 1996, p. xxv).

Outro tópico que merece destaque é a utilização das figuras. São importantes referenciais, mas nem por isso tornam a literatura mais fácil. Nodelman (2002, p. 70) afirma que "figuras comunicam de forma mais natural e direta que palavras, ajudando aos jovens leitores a dar senso aos textos que os acompanham"2. No entanto, ver um desenho requer do "leitor" a noção de entender as suas características. Por exemplo, continua Nodelman, o leitor deveria saber que: a perspectiva surgiu somente na

[pictures communicate more naturally and more directly than words, and thus help young readers make sense of the texts they accompany] $A$ tradução desta citação e de todas as seguintes, em que o original aparece em notas de rodapé, são de minha autoria. 
Renascença; os objetos mais afastados aparecem menores do que os mais chegados; o tamanho de pessoas e objetos é subjetivo; não é possível incluir todos os detalhes que um olho humano captaria se estivesse presente na cena; há diversos estilos e propósitos no mundo dessa arte; as cores e formas mexem com as emoções de maneira estritamente particular; as palavras que acompanham as figuras têm relação com elas; o leitor precisa saber quem é o narrador do texto e quem é o personagem que aparece nas figuras (NODELMAN, 2002, p. 71).

É neste ponto que Nodelman (2002, p. 72) atrela essa "tradução" à semiótica (que Torop denominou de extratextual), afirmando que "pensar sobre livros ilustrados em termos semióticos é a nossa ferramenta mais valiosa na tentativa de compreendê-los"3. No caso de um personagem, a sua roupa revela algumas das facetas do seu portador, como se vê nos desenhos de Busch. Ela pode revelar a posição social, o sexo, a idade, a simpatia ou antipatia. Os desenhos já carregam consigo uma conotação cultural, referindo-se aos eventos que descrevem (NODELMAN, 2002, p. 74).

Não há, portanto, razão para adaptar os desenhos, modificá-los ou promover outra atitude qualquer a não ser a sua manutenção. Através das gravuras e dos versos, pretende-se criar uma leitura dinâmica, fácil, acessível, de tal modo que nem mesmo a criança de até 10 anos necessite recorrer a um dicionário ou à explicação de algum vocábulo por parte de um adulto, senão em casos esporádicos, quando da introdução de algumas palavras mais rebuscadas para o público almejado.

\section{Escolhas do título e do prólogo}

O título já apresenta o nome dos personagens principais. As suas características relevantes são mostradas logo no prólogo, bem como a advertência de seu trágico fim.

$O$ título faz parte da paratextualidade, assim como o subtítulo e as figuras (CASCALLANA, 2006, p. 100). A versão inglesa (Max and Moritz) manteve os nomes originais no título. Em muitos casos, o nome do personagem principal também faz parte do título, como ocorre na presente obra. Seguindo a tendência atual e outras versões de Max und Moritz, mantive

3 [thinking of picture books in semiotic terms is our most valuable tool in coming to understand them]. 
os nomes originais. Entretanto, no caso do Brasil, como já existe uma tradução da obra em português com outros nomes, isto é, outro título (Juca e Chico: história de dois meninos em sete travessuras ${ }^{4}$ ), surge um impasse: manter o nome tradicional já traduzido ou fornecer uma nova versão de título?

Existem duas possibilidades: se o primeiro trabalho, a primeira tradução for já notadamente consagrada pelo público, mudar o seu nome traria resultados negativos; se, por outro lado, a nova proposta for audaciosa o suficiente, ela poderá desvincular-se da antiga referência.

Analisando a trajetória da tradução "Juca e Chico", constata-se que foi conhecida por gerações mais antigas. Um dos fatores que talvez exerça alguma influência é a idade da tradução, a qual já ultrapassa um século de existência. Como resultado, tem-se uma obra fora dos padrões vocabulares do século XXI. Há palavras arcaicas e desconhecidas. As obras precisam de revisões constantes, pelo menos a cada trinta, quarenta ou cinquenta anos (LANDERS, 2001, p. 10-11). Neste caso, a tradução já está defasada há pelo menos duas ou três vezes esse tempo.

Para um público de quatro a dez anos de idade, a leitura daquela de 1901 se torna como que infrutífera, com lapsos de compreensão. Efeito semelhante se percebe também no público adulto. São razões suficientes para uma nova tradução.

Quanto aos nomes, a permanência dos originais Max e Moritz também se justifica. Klinberg (1986, p. 43) e Cascallana (2006, p. 103) são de opinião que os nomes permaneçam tal qual estão no original, especialmente aqueles que não possuem nenhum significado em especial ou aqueles que sejam comuns. Caso tenham algum significado, seria melhor traduzi-los, a fim de que o público-alvo receba a informação ou conotação que o nome carrega. Max e Moritz eram nomes comuns na Alemanha no século XIX, não tendo nenhum significado especial para o texto em si. Max não causa dificuldades. $O$ único estranhamento seria o nome Moritz. Mas o estranhamento não é necessariamente um aspecto negativo, como van Coillie (2006, p. 124) afirma:

caso ele ou ela [tradutor(a)] use os nomes tais quais como estão, há um risco de se ter um outro efeito daquele originalmente proposto

4 Tradução de Olavo Bilac, em 1901. 
pelo autor: o nome pode ser difícil de ser pronunciado, por exemplo, ou pode não ter a conotação desejada na língua de chegada 5 .

No caso de Moritz, embora exija uma articulação incomum para os falantes da Língua Portuguesa, tem na palavra "Blitz" um referencial de pronúncia. $O$ estranhamento é um fator positivo sob diversos aspectos, pois identifica uma cultura diversa daquela em que se vive, contribuindo para a ampliação de horizontes (STEINER, 1998, p. 92).

Ainda quanto à manutenção dos nomes originais, Fernandes (2004, p. 148) analisou a tradução de nomes de quatro obras recentes ${ }^{6}$ e constatou que, de um total de 269 nomes ali usados, 195 foram simplesmente copiados (mantidos como no original), enquanto apenas dois foram substituídos, trocados por nomes diferentes. Isto é importante observar, pois "Juca" e "Chico" são substituições, procedimento incomum em traduções dessa natureza atualmente.

Já Aguilera (2008, p. 3) considera o nome próprio uma categoria gramatical como outra qualquer, sendo passivel de tradução se ela tiver um papel importante de significado. Neste caso, poderia ser considerada a possibilidade de verter "Moritz" para o seu correspondente em português, ou seja, Maurício. Isto traria tanto problemas como soluções. Entre as soluções, proporcionaria uma identidade e pronúncia fácil de assimilar; entre os problemas, aumentaria a palavra em uma sílaba e impediria a métrica "trochaia" (veja adiante) com Max.

Aguilera também diz que há fatores que interferem na escolha do tradutor de literatura infantil. Um deles seria a idade. A escolha pode recair sobre três grupos distintos: 1) pré-alfabetizado (0 a 6 anos); 2) alfabetizado ( 6 anos à adolescência); e 3 ) adolescência e juventude (AGUILERA, 2008, p. 4).

Quanto mais cedo se expõe a criança a uma nova língua ou a uma nova cultura, mais facilidade ela tem de incorporar elementos estrangeiros. É fácil deduzir que nomes estrangeiros não vão interferir negativamente na aquisição do conhecimento de uma criança tão acostumada ao mundo globalizado.

5 [if he or she uses the names as they are, there is a risk that they may have another effect than the originally intended by the author: the name may be too difficult to read, for example, or it may not have the desired connotations in the target language]

6 Harry Potter and the Philosopher's Stone; Artemis fowl; The Chronicles of Narnia; The Worlds of Christomanci. 
Tendo em mente o público-alvo, os nomes devem ficar como estão. Devido ao pouco conhecimento atual dessa obra, tanto do original quanto da tradução anterior, o novo título parece ter méritos suficientes para ocupar o seu lugar na literatura.

O segundo tópico é quanto à manutenção da forma do texto original. Busch escreveu sua "miniepopeia" em um dos cerca de 30 tipos de pés métricos alemães (Versfüße). Ele escolheu o que se estrutura em sílabas binárias onde há alternância de tônicas e átonas. Cada verso tem quatro desses pés binários, chamados de "Trocaios" ou "troqueu" (Trochäus), sendo que o último pé pode abrir mão da sílaba átona. Em suma, os versos somam 7 sílabas em que predomina a rima rica. Ela aparece na sequência aa, bb, $c c$, etc. Além disso, Busch dá aos versos um ritmo, uma cadência conseguida pela tonicidade dos pés métricos "Trocaios" (das sílabas ímpares 1, 3, 5, 7.) $e$ atonicidade das sílabas pares de um verso. Tal proeza e mobilidade se conseguem pela peculiaridade da língua alemã ter um vasto vocabulário monossilábico tônico, quando comparado à Língua Portuguesa, bem aproveitado por Busch. Alguns exemplos simples: Wort (1) > palavra (3); schwer (1) > pesada (3); Pfanne (2) > frigideira (4). Esta maior envergadura das palavras portuguesas obriga a uma reformulação de sua ordem ou a um enxugamento do conteúdo em certos aspectos. Em compensação, o fato de existirem mais palavras da Língua Portuguesa que começam ou terminam em vogal contribui na junção das sílabas poéticas, diminuindo o seu número.

Além disso, havia a necessidade de escolher uma forma correspondente ao trocaio na língua portuguesa, e a que mais se enquadrou no esquema de Busch foi a redondilha maior. Escrita em sete sílabas poéticas, ela consegue suprir vários aspectos necessários para repassar a mesma forma e conteúdo. Assim, seria possível transpor o pé métrico para o português, bastando alternar entre sílabas tônicas e átonas no verso, ou meIhor, fazer com que todas as sílabas ímpares fossem tônicas e as pares, átonas. Desse modo, manteve-se a forma original adaptada, tanto na parte das rimas, quanto nos ritmos e na métrica. Têm-se rimas $a a, b b, c c$, etc, ritmo ditado pela tonicidade das sílabas poéticas ímpares e versos de sete sílabas, a redondilha maior. Isto significa dizer que, nos moldes propostos por Torop (OSIMO, 2004, cap. 22), a forma e o conteúdo da expressão dominam a tradução de modo que o suposto efeito causado no leitor do original venha a ser aplicado ao leitor do texto de chegada, quer dizer, existe a preocupação com o resultado, o efeito semelhante. 


\section{Primeira travessura}

A primeira travessura tem como alvo uma viúva de nome Bolte. Ela tem três galinhas e um galo em seu quintal. Max e Moritz provocam a morte das aves, que se enroscam e se enforcam num galho de árvore.

Nesta travessura, Busch apresenta a viúva, o terceiro personagem. Na verdade, Bolte é sobrenome, pois é um hábito comum na Alemanha e na Europa, de onde vem esta história, identificar a pessoa pelo sobrenome. Bolte em si não tem nenhum significado especial. Por esta razão não requer tradução.

Porém, existe um diferencial quando este hábito da cultura europeia é aplicado no Brasil. Não é comum referir-se a uma mulher pelo sobrenome. O normal é mencioná-la pelo nome. Já para o homem, tal costume europeu é mais aceitável, já que este carrega consigo o nome de família, ao passo que a mulher o perde a fim de usar o nome (sobrenome) do marido, embora a Lei brasileira atual faculte o uso à mulher ou permita ao homem adotar o sobrenome da companheira.

Mas se o sobrenome não for de origem brasileira ou portuguesa, torna-se mais fácil tal aplicação. Uma das explicações seria a dificuldade do brasileiro em reconhecer e/ou diferenciar o que seria o nome ou o sobrenome dos imigrantes. A estratégia utilizada foi a transnacionalização, quer dizer, a manutenção do nome (sobrenome) Bolte, justamente para dar o tom de estranhamento, a fim de que o leitor tenha a noção de se tratar de uma obra intercultural (HAGFORS, 2003, p. 125).

Analisando ainda as recomendações de van Coillie (2006, p. 131), lemos: "os nomes nos poemas podem ser substituídos por causa da rima $e$ da métrica"7. De fato, os nomes estrangeiros - aqui no caso, os alemães apresentam esta característica da dificuldade da rima em português. "Bolte" tem poucos pares de rima, o que oferece parcas opções no verso. Uma das soluções mais pertinentes para suprir a falta de vocabulário seria manter o nome intercalado no verso, caso não houvesse encontrado o par de rima ideal.

Mais adiante aparece uma onomatopeia. O texto alemão diz: "Kikeriki! Kikikeriki!!! / Tak, tak, tak!". Tais onomatopeias são estranhas ao público brasileiro. Na visão de Pascua-Febles (2006: 117), "não é muito recomendável manter as expressões estrangeiras. Para estes marcadores, os tra-

\footnotetext{
7 [names in poems can be replaced for reasons of rhyme and metre]
} 
dutores tendem a seguir as convenções textuais e as normas linguísticas da cultura receptora"8. Por esta razão, o canto do galo tornou-se "cocoricó". Porém, para formar o verso em sete sílabas, foi necessário reduzir o primeiro canto para "cocricó", a fim de acentuar a terceira sílaba, coincidindo a tonicidade do "canto do galo" na sétima sílaba. Assim, temos "Cocricó! Cocoricó!".

Já o som típico das galinhas contentes pela comida foi mudado de "tak, tak, tak" para "poc, poc, póó!", sendo o último mais longo, como um som típico dessas aves. De um lance só foi resolvido o problema da onomatopeia e da rima.

Mais adiante temos um lamento, expresso em alemão como "Ach herrje, herrjemine!", posto como "Jiminee, O Jimini!" em inglês. Trata-se de uma expressão (interjeição) em desuso na língua alemã ( $A$ ch, Herr Jesus). No português, tentando resgatar um pouco esse aspecto da referência religiosa, aparece o lamento "ai, meu Deus, Jesus, João".

A narrativa continua $e$ as aves ficam penduradas num galho de macieira, informação omitida aqui, cabendo à criança a definição da espécie de árvore que desejar. De um modo geral, o conceito de pé de maçã que se tem no Brasil é aquele das plantações comerciais, e jamais teriam o porte avantajado apresentado na figura.

\section{Considerações finais}

Embora toda tradução produza um resíduo tradutório, é salutar que o tradutor almeje conduzir com êxito o seu empreendimento e vê-lo concluído.

Como se vê, o exercício tradutório é algo fascinante e pode levar a tantos caminhos e possibilidades que o seu resultado não se torna estático, mas dinâmico e vivo no mundo da tradutologia.

\section{Referências}

AGUILERA, Elvira Cámara. The translation of proper names in children's literature. Granada (Spain): University of Granada, s.d.

8 [it is arguably not appropriate to retain foreign expressions. For these markers translators are more likely to follow the textual conventions and linguistics norms of the target culture] 
AMORIM, Frederico. "Alemanha". Página eletrônica: mundofred.home. sapo.pt/paises/pt/alemanha.htm. Consulta realizada em 16 de abril de 2009.

BENTON, Michael. "Readers, texts, contexts: reader-response criticism". In: HUNT, Peter (Ed.). Understanding children's literature: key essays from the International Companion Encyclopedia of Children's Literature. London/New York: Taylor \& Francis e-Library, 2002, p. 81-99.

BUSCH, Wilhelm. Juca e Chico: história de dois meninos em sete travessuras, tradução de Olavo Bilac. 11 ed. São Paulo: Melhoramentos, s.d. Página eletrônica: www.unicamp.br/iel/memoria/Ensaios/Literatura Infantil/jucaechico/jcindice.htm. Consulta realizada em 19 de março de 2009.

BUSCH, Wilhelm. Max und Moritz: eine Bubengeschichte in sieben Streiche. [s.l.]: Eklinger, 1992. il. Color.

CASCALLANA, Belén González. "Translating cultural intertextuality in children's literature". In: COILLIE, Jan Van; VERSCHUEREN, Walter P. (Ed.). Children's literature in translation: Challenges and strategies. Manchester: St. Jerome Publishing, 2006, p. 97-110.

COILLIE, Jan Van. "Character names in translation: a functional approach". In: COILLIE, Jan Van; VERSCHUEREN, Walter P. (Ed.). Children's literature in translation: challenges and strategies. Manchester: St. Jerome Publishing, 2006, p. 123-139.

DOONAN, Jane. Looking at pictures in picture-books. South Woodchester: Thimble Press, 1993, p. 7.

FERNANDES, Lincoln P. Practices of translating names in children's fantasy literature: a corpus-based study. Unpublished Doctor Thesis. Universidade Federal de Santa Catarina, Florianópolis, 2004.

GLASER, Hermann; LEHMANN, Jakob \& LUBOS, Arno. Wege der Deutschen Literatur: eine geschichtliche Darstellung. Berlin: Ullstein, 1987, p. 370.

HAGFORS, Irma. The translation of culture-bound elements into Finnish in the Post-War period. Meta Translator's Journal, vol. 48, n. 1-2, maio 2003, p. 115-27.

KLINBERG, Göte. Children's fiction in the hands of the translators. Lund (Sweden): CWK Gleerup, 1986.

LANDERS, Clifford E. Literary translation: a practical guide. Clevedon: Multilingual Matters Ltd, 2001. 
MITTELBERG, Ekkehart. "Metrum und Rhythmus II: beliebte Versfüße". Página eletronica: https://autorenweb.de/abfrage_texte.ph-p3?id=8335. Consulta realizada em 16 de julho de 2009.

NODELMAN, Perry. "Decoding the images: illustration and picture books". In: HUNT, Peter (Ed.). Understanding children's literature: key essays from the International Companion Encyclopedia of Children's Literature. London/New York: Taylor \& Francis e-Library, 2002, p. 69-80.

OSIMO, Bruno. "Curso de tradução", tradução de Mauro Ramos da Silva e Nádia Aparecida Fossa. Curso on-line gratuito. @ 2004. Página eletrônica: http://courses.logos.it. Consulta realizada em 16 de maio de 2008.

PHILIP, Neil (ed.). The new Oxford book of children's verse. Oxford: Oxford University Press, 1996.

SHAVIT, Zohar. Poetics of children's literature. Athens and London: University of Georgia, 1986. Chapter 5, p. 110-30. Página eletrônica: http:/ /www.tau.ac.il/ zshavit/pocl/five.html. Consulta realizada em 30 de janeiro de 2009.

STEINER, George. Depois de Babel, tradução de Carlos Alberto Faraco. Curitiba: UFPR, 1998.

TOROP, Peeter. La traduzione totale, tradução para o italiano de Bruno Osimo. Modena: Logos via Curtatona, 2000.

VAßEN, Florian. "Busch, Wilhelm". In: LUTZ, Bernd (hrsg). Metzler Autorenlexikon: Deutschsprachige Dichter und Schrifsteller vom Mittelalter bis zum Gegenwart. Stuttgart: Metzler, 1986, p. 95-7.

WIKIPEDIA, die freie Enzyklopädie. "Versfüâe". Página eletrônica: http:/ /de.wikipedia.org/wi-ki/Versfuß. Consulta realizada em 16 de julho de 2009. "Wilhelm Busch". Página eletrônica: http://de.wikipedia.org/wiki/ Wilhelm_Busch. Consulta realizada em 23 de fevereiro de 2009. 